\title{
Understanding user attitudes and economic aspects in a corporate multimodal mobility system: results from a field study in Germany
}

\author{
Madlen Günther ${ }^{1 *}$, Benjamin Jacobsen², Marco Rehme ${ }^{2}$, Uwe Götze ${ }^{2}$ and Josef F. Krems ${ }^{1}$
}

\begin{abstract}
The present study aims to investigate user attitudes and behaviour when users interact with a corporate multimodal mobility sharing system, consisting of battery electric vehicles (BEVs), pedelecs (i.e. electric bicycles) and public transport. We analysed participants' attitudes towards BEVs, pedelecs, public transport, and the underlying service tools, as well as the economic impacts of the whole corporate multimodal mobility system. Ninety-three participants took part in the 22 months long naturalistic driving study and used the corporate multimodal mobility sharing system for their business travel. The attitudes towards BEVs and the keyless access were evaluated as the most positive components, and usage behaviour was related to a more positive attitude towards pedelecs, public transport, as well as the keyless access and the booking tool. The economic evaluation revealed the possibility of significant reductions in mobility costs when integrating different means of transport into a smart multimodal mobility system. The findings may help fleet owners to further improve existing mobility concepts for corporate travel.
\end{abstract}

Keywords: Corporate Mobility as a Service (CMaaS), Field study, Usage behaviour, Experience, In-company mobility solution, Battery electric vehicles, Pedelecs, Public transport, Business models, Life cycle costing, Opportunity costs

\section{Introduction}

Variants of shared mobility are promising solutions for a sustainable transportation future, given the associated reductions in average vehicle ownership [25], emissions [9] and travelled kilometres [33]. The availability of shared mobility services also resulted in a mobility shift, mostly characterised by an increase in the use of bicycles and walking, as well as the usage of carpooling [25]. Further, shared mobility solutions are a more appropriate

\footnotetext{
* Correspondence: madlen.guenther@psychologie.tu-chemnitz.de A previous version of this article [13] was presented at the International Conference on Mobility as a Service (ICoMaaS) 2019 and has been selected from the ICoMaaS 2019 papers for the Topical Collection "Developing Mobility as a Service - User, operator and governance perspectives" in the European Transport Research Review journal.

${ }^{1}$ Cognitive \& Engineering Psychology, Technische Universität Chemnitz, 09107 Chemnitz, Germany

Full list of author information is available at the end of the article
}

way for vehicle provisioning with a substantial market potential [4]. At the same time, they enable a more efficient use of resources through a higher degree of vehicle utilisation with a potentially larger user pool, compared to an exclusive provision for a specific user or company. Furthermore, shared mobility users reported lower commuting stress compared with single-occupant vehicle users [8]. Multimodal mobility, defined as the usage of a transportation network with diverse transport modes for the needs of mobility [11], seems to be a promising path to further improve the positive environmental benefits of single-mode sharing systems. The integration of bicycles and public transport are suitable examples for this. Beyond that, ride sharing has established itself as another popular mode of travel and a viable business model [40] that could be combined with classical car 
sharing and multimodality. The positive effect of cycling relates to reduced emissions and traffic congestion [36], as well as reduced travel costs [22]. In addition, active mobility has a positive effect on physiological health parameters such as obesity [2] and cardio-vascular risk [15], as well as on mental health parameters such as well-being [24]. Positive aspects of the usage of public transport are less greenhouse gas emissions and a relaxation of traffic problems caused by a high amount of individual transport [35].

However, to the best of our knowledge, there are no previous studies in which a field-tested multimodal sharing system has been examined for its user acceptance and economic efficiency, comparing the means of transport contained therein.

\section{Theoretical and conceptual background}

\subsection{Corporate multimodal mobility systems}

As mobility for business journeys accounts for a high proportion of daily kilometres travelled and greenhouse gas emissions [26], supporting the use of more environmentally friendly means of transport for business journeys is a promising approach. In this regard, several companies use a company-owned fleet or in-company mobility solutions. However, conventional corporate mobility systems with accounting per business journey are still predominant.

In smart(er) corporate multimodal mobility solutions several modes of transport are accessible. Such solutions can be considered as Mobility as a Service (MaaS) in a corporate setting, meaning that they are controlled by a corporation and used by employees for travelling to, from, in or between work sites or campuses [16]. MaaS is understood as the "integration of various forms of transport services into a single mobility service accessible on demand" [23]. MaaS adds value through the usage of a single ICT application to provide a smart access to mobility. Corporate MaaS (CMaaS) solutions can be seen as "sandbox" versions of well-functioning general MaaS implementations and be used to gather first experiences, since their usage is limited to a businessrelated context where many of the contextual variables are easier to control [16]. One example of a CMaaS solution is the use of an in-house pool of company cars based on a booking platform and with access to additional transport modes. But CMaaS solutions can also be implemented without in-house fleets. The economic viability of the operation of such systems depends on several factors, such as integrated means of transport, type of vehicle use and travel, usage scenarios, drive technologies, as well as the underlying procedures and tools. For instance, mobility costs of in-house, B2B shared or third-party vehicle fleets can vary significantly and depend on the number of employees using the vehicles successively or simultaneously. Efficient, software-supported business processes can reduce the overhead costs of business journeys. Furthermore, not all means of transport are suitable for every type of travel (e.g. bicycle vs. long-distance traffic) whereas other manifestations of a mobility solution fit together quite well (e.g. fixed carpooling for commuting between homes and work).

Based on these considerations, Fig. 1 shows a morphological box for a possible classification of CMaaS solutions.

The blue marked boxes represent the manifestations of the CMaaS solution addressed within this paper. Noteworthy (especially for the interpretation of the economic results) is that the CMaaS solution under consideration differs from conventional corporate mobility systems in two main points. On the one hand, it integrates ecologically sustainable company vehicle fleets with public transport services. On the other hand, it also renounces traditional accounting systems for business journeys to increase further potentials that come with a multimodal platform.

\subsection{The link between user research and economic feasibility of CMaaS}

In order to better understand users' travel mode choices, the acceptance of, and attitudes towards different means of transport need to be examined [16]. Several existing publications study users' acceptance of car sharing and ride sharing systems (e.g. [22, 39]) and the influence of user attitudes on bus and car use (e.g. [1]). Attitudes towards a certain behaviour have been successfully proven to be a useful predictor of a certain behaviour [10]. In the context of travel mode choice, research shows that attitudes towards bus, car and bicycle are quite stable [1]. However, from battery electric vehicle (BEV) research we see that attitudes can be positively affected by experience and usage $[5,6]$.

Current mobility research also addresses economic aspects of multimodal mobility solutions, especially for the public in inner-city areas. Many recent studies focus on integrating BEVs and electric bicycles (i.e. pedelecs) in mobility chains, as for example one for the city of Chemnitz and the Ore Mountains district [17]. Other studies $[29,34]$ concentrate on the combination of public transport with automated vehicles for feeder traffic and their potentials for economic efficiency. Particularly questions related to the economic viability of alternative mobility concepts like CMaaS are being intensively investigated at the moment. Although a great number of challenges show up due to the early stage of development, previous studies conclude that CMaaS is a promising business opportunity $[19,21]$. However, the academic discourse on the economic implications of 


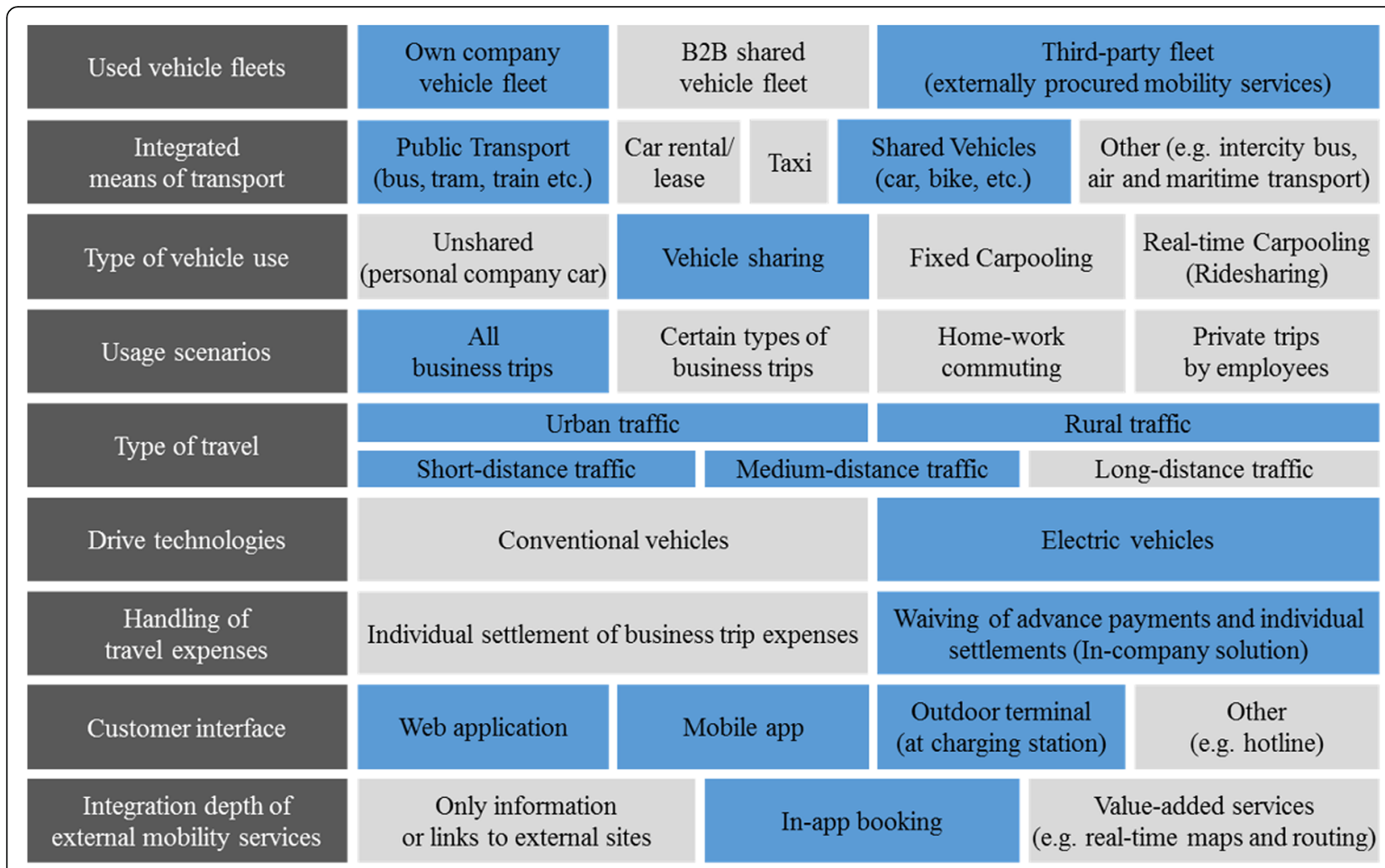

Fig. 1 A possible classification scheme of CMaaS solutions

CMaaS and other multimodal mobility concepts is still in its infancy with economic advantages that still need to be proven and, (if beneficial) with optimal configurations and resource allocations that have yet to be determined. Since most of the existing trials and analyses are limited to experimental testing, specific application fields or sub-problems, many research questions remain unanswered.

Overall, there is a great need for further research into viable implementations of multimodal mobility solutions. For successful realisations and the large-scale use of sustainably promising mobility systems, experiences must be gained by (and examined for) potential user groups, which can significantly increase acceptance among them. Furthermore, the link between user acceptance and the generation of economic benefits for the involved stakeholders is particularly interesting since both might mutually influence each other. Thus, the research fields of psychology and economics are of great importance for the success of innovative mobility systems. Our results provide a humble contribution to acquire knowledge in this field.

\subsection{Present research}

The aim of the present research was to investigate participants' attitudes towards different means of transport (i.e., BEVs, pedelecs, and public transport) and the underlying mobility service tools (i.e., keyless system access, web-based booking tool, and the online ticket system linked to a corporate account for paying for public transport journeys) which were necessary in order to offer a CMaaS system. We investigated the influence of usage (i.e., travelled kilometres with BEVs, pedelecs and public transport) on participants' attitudes, analysed associated mobility costs of the three means of transport and carried out an economic evaluation of the whole CMaaS system.

To offer a sustainable transport system it is necessary to ensure economic advantages in viable business models (i.e. according to Schallmo [32] the simplified representations of an enterprise's business logic, consisting of interlinked elements). Our related investigations were based on approaches for business model development and selection according to Rehme et al. [28], the evaluation and description model according to Schallmo [32] and life cycle costing [12] for an economic evaluation. With data obtained in the project we investigated the economic efficiency of a presumably more ecologically sustainable CMaaS system (see [4]). This CMaaS solution represents one of the promising approaches according to a work by IVM Institut für Vernetzte Mobilität gGmbH [18], in which a large number of business models were designed and evaluated. 
For the investigation purposes in the main areas of interest of this paper we address the following research questions $(\mathrm{Q})$ :

Q1: What attitudes towards the three means of transport (BEVs, pedelecs, public transport) and the underlying mobility service tools (keyless system access, web-based booking tool, online ticket system linked to a corporate account for paying for public transport journeys) were reported?

Q2: What influence does usage (i.e. travelled kilometres with BEVs, pedelecs and public transport) have on participants' attitudes?

Q3: What economic costs are related to the three means of transport?

Q4: Should in-company mobility solutions be provided or is the conventional system with per business journey accounting economically advantageous?

The article is structured as followed: Chapter 3 describes the methodology of the study, the participants and measurements. Chapter 4 contains the results and addresses the four research questions. In the last chapter, we summarise the results, discuss them and derive implications for research and practice. Finally, a conclusion is given.

\section{Methodology}

\subsection{Study setup}

We used data from a 22 months long-term naturalistic driving study [3], implementing a CMaaS system to investigate mobility behaviour and user acceptance in interaction with new mobility systems. Study participants were employees at Technische Universität Chemnitz, Germany.

The University has approximately 2500 employees and is located in a hilly medium-size city with approximately 247.000 inhabitants and an above-average proportion of academics. Its facilities are spread over four locations (one in the city centre, two close to the city centre and one on the outskirts) within a distance of three to eight kilometres. The outer area of the city is characterised by suburban and rural districts with variable altitude profiles. A significant share of employees commutes from other municipalities.

Study participants had free access to four BEVs, eight pedelecs and the public transport network for their business journeys (i.e., only for business travel; no home-towork travel). A charging infrastructure and a web-based booking application (i.e., ICT solution) were also provided. For using public transport an additional online ticket had to be booked, provided by an additional web application. Thus, the payment could be made via an online ticket system and corporate account. In order to use a vehicle, participants first had to select the start, destination and time of the desired journey via the web-based booking tool (Fig. 2, left). Depending on vehicle availability (Fig. 2, middle), the preferred means of transport was selected. Finally, the arrival time was specified, and the booking was confirmed. Afterwards, participants

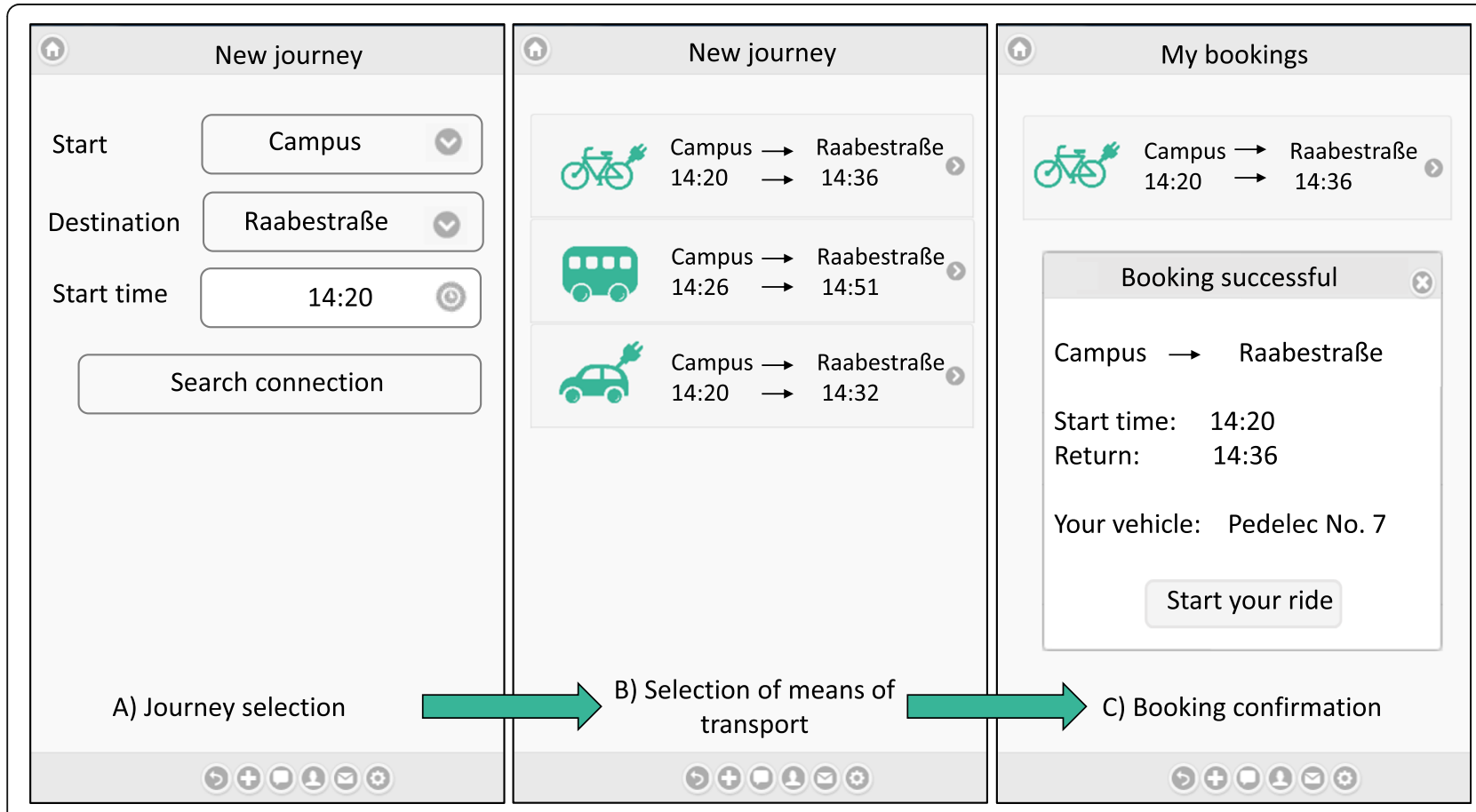

Fig. 2 The booking process via the web-based booking tool 
received a reservation confirmation (Fig. 2, right). Figure 2 represents the booking process.

Participants only needed their employee ID card to get access to the BEVs (keyless system access). In order to use the pedelecs, participants received the PIN for opening the bicycle lock. Public transport access was possible by a QR-code, which could be retrieved with the reservation confirmation via an additionally connected online ticket system.

Before their first system access, all participants received a comprehensive technical briefing about the mobility sharing system, including how to use the three means of transport and the booking tool, the scope and extent of data collection, and their conditions of use (e.g., restricted only to business travel; no home-to-work travel). Participants filled out two online questionnaires after four and after 6 months of system usage. We assessed participants' usage behaviour and their attitudes towards the three means of transport (BEV, pedelec, public transport) and underlying mobility service tools (keyless system access, web-based booking tool, online ticket and corporate account).

\subsection{Participants}

Interested university staff were invited to take part in the study via newsletter, press release and study homepage and were required to fulfil the following inclusion criteria: (1) active employment with Technische Universität Chemnitz because of aspects of insurance law (e.g., not on parental leave), (2) participation in data collection, and (3) acceptance of the legal conditions of use (e.g. only business journeys). Out of 284 applicants, 93 participants fulfilled the criteria and had completed data collection in the online questionnaire after four and after 6 months. The sample consisted of 21 women and 72 men ranging from 21 to 64 years old ( $M=35$ years, $S D=9.3$ ). $73.1 \%$ of the participants were university educated, $21.5 \%$ were technical or administrative personnel and $5.4 \%$ were students with employment contracts.

In the application questionnaire (before study participation) participants reported to travel on average $21.7 \mathrm{~km}(S D=34.06, \operatorname{Min}=0, \operatorname{Max}=174)$ with car, $7.3 \mathrm{~km}(S D=13.46, M i n=0, \operatorname{Max}=75)$ with bicycle and $10.1 \mathrm{~km}(S D=29.72, \operatorname{Min}=0, \quad \operatorname{Max}=180)$ with public transport on a typical work day (including private journeys).

This study was carried out in accordance with the American Psychological Association Code of Ethics, as well as recommendations, regulations and consent templates of the Technische Universität Chemnitz ethics commission. All subjects gave written informed consent.

\subsection{Measurements and calculations}

We used a combination of subjective questionnaire data to assess participants' attitudes, objective driving data from the booking tool to assess usage in kilometres by the three means of transport and several cost calculations for the operating organisation.

Participants' usage behaviour and attitudes towards the three means of transport and underlying mobility service tools were assessed after four (T1) and after six (T2) months of system usage with two online questionnaires.

\subsubsection{Attitudes towards means of transport and underlying mobility service tools}

We used single stimulus statements to assess participants' attitudes towards each of the three means of transport and service tools. Items were: "I like the electric vehicles used in the project (Smart fortwo, electric drive)", "I like the pedelecs used in the project", "I like the possibility of using public transport in the project", "I like the keyless access to the vehicle via the employee ID card", "I like the booking system (available via PC, smartphone and at the charging station)", "I like the online ticket system with the corporate account for paying for public transport journeys". All items were answered on a six-point Likert scale from 1 (strongly disagree) to 6 (strongly agree).

\subsubsection{Mobility data}

Via the booking tool we assessed the number of participants' journeys using the three means of transport (BEVs, pedelecs and public transport) and the travelled kilometres until T2. We define a journey as all travelled kilometres between the successful booking via the system (i.e., click the button "start your ride" in the booking tool) and the return of the borrowed vehicle or the definite exit from public transport (i.e. click the button "end your journey" via the booking tool). Several stops were possible within one journey. We recorded a total number of 799 journeys corresponding to 12024 travelled kilometres with the three means of transport (BEVs: 501 journeys and $7666 \mathrm{~km}$, Pedelecs: 174 journeys and $1350 \mathrm{~km}$, public transport: 124 journeys and $3008 \mathrm{~km}$ ). Table 1 represents the average and maximum travelled kilometres and number of journeys until T2 for each means of transport. Each participant drove on average $64 \mathrm{~km}$ with the BEVs, travelled $14 \mathrm{~km}$ with the pedelecs and $27 \mathrm{~km}$ with public transport. There were on average six journeys made by the BEVs, and two journeys each by the pedelecs and public transport per participant. BEVs were used most frequently (most driven kilometres and number of journeys), followed by pedelecs and public transport. 
Table 1 Participants' average and maximum travelled kilometres and number of journeys until T2

\begin{tabular}{lllll}
\hline & $\boldsymbol{M}_{\boldsymbol{k m}}(\boldsymbol{S D})$ & $\boldsymbol{M a x}_{\boldsymbol{k} \boldsymbol{m}}$ & $\boldsymbol{M}_{\text {journeys }}$ & Max $_{\text {journeys }}$ \\
\hline BEV & $63.81(103.53)$ & 440 & $5.39(10.50)$ & 75 \\
Pedelec & $13.47(29.34)$ & 140 & $1.87(5.74)$ & 37 \\
Public transport & $26.75(83.65)$ & 550 & $1.33(4.56)$ & 25
\end{tabular}

$N=93$. Because some participants made no business journeys, for each means of transport Min $=0$. Max referred to maximum total number of travelled kilometres/journeys after 6 months of system access

Before the implementation of the CMaaS system, there was no possibility of using company bicycles or pedelecs. Billing paper tickets for public transport was possible, but very complex and time-consuming. As a result of the implementation of the CMaaS system, the proportion of business journeys by pedelec and public transport has increased significantly.

The average distance travelled for business journeys at Technische Universität Chemnitz is $6 \mathrm{~km}$ within the city area. The number of journeys with all means of transport per employee and per week is 1.32 in the summer half-year (April - September) and 1.65 in the winter half-year (October - March). This distance and number of journeys apply to $48.48 \%$ of the employees. All other employees have either a really low volume of business journeys or rather many long-distance business journeys (travelled by plane, for example), that could not be covered by the trialled CMaaS concept. Regarding the pedelecs and the range of the BEVs (up to $120 \mathrm{~km}$ ) a special kind of journey in the city area was under investigation.

\subsubsection{Cost calculations and economic evaluation approach}

The economic results presented in chapter 4 are based on cost calculations for the operating organisation, considering all relevant cost components of the CMaaS system from a life cycle point of view.

We assessed the total travel-related costs for business journeys (e.g., for acquisition, operation and maintenance of company vehicles and infrastructures (charging stations, IT-equipment) and associated service staff, payments for external transport services, as well as opportunity costs) for each means of transport. In addition to costs that can be directly allocated to the cost units (passenger car, pedelec, public transport rides), other (indirect) travel-related costs also occur. Forecasting these costs is especially difficult, since they depend on many parameters that cannot be controlled. For example, additional costs for an electronic public transport ticket management system largely depend on the local transport operator, while costs for the installation of charging points are strongly dependent on the respective location conditions. For this reason, these values were added to the total costs as a fixed component in a combined package and apportioned pro rata to the vehicle kilometres. Other system costs include costs for support, the administration of the booking tool, as well as for hardware and software. In order to be able to compare different means of transport fairly, additional opportunity costs (OC) must be taken into account. These opportunity costs represent the loss of working time which may arise from the increased transit times with slower means of transport (see Fig. 3); the consequent reductions in effective working time should be considered in a monetised manner, as they were implemented in our calculation.

From an economic point of view, the purpose of a CMaaS system should be to reduce the total accumulated costs for business journeys. As benchmark for the status quo the common and currently used conventional system per business journey accounting was used. This system implies the use of a means of transport as chosen by the user within the specifications for billable travel expenses. Before and after the journey administrative effort is necessary. This effort includes the preparation of the business journey application and of the claim-forms for reimbursement, the signature and verification by superiors, and the verification and the settlement by the travel cost centre. So, with every business journey an enormous overhead is generated. Suitable solutions to reduce these overhead costs of business journeys are the provision of a company-owned vehicle pool or the participation in a CMaaS system that waives advance payments and individual settlements. With these solutions, the administrative effort can be reduced if the conventional system is abolished. A comparison shows which approach for corporate mobility is economically advantageous.

\section{Results}

4.1 User' attitudes towards the three means of transport and underlying service tools

The descriptive statistics of the reported user attitudes towards the three means of transport and service tools between T1 and T2 are displayed in Table 2. Participants reported consistently positive attitudes towards the three means of transport and the service tools (i.e., all ratings were above the scale mean). As there were no differences in the reported attitudes between T1 and T2 (all $p$-values $<.274)$, we also give mean scores for the two combined.

To analyse our first research question (Q1) we conducted two ANOVAs and tested differences between mean attitudes $\left(M_{\text {mean }}\right)$ towards the three means of transport and the three underlying mobility service tools separately. Analyses revealed significant differences in participants' attitudes towards means of transport $(F(2$, 184) $\left.=5.69, p=.004, \eta_{p}^{2}=.06\right)$ and underlying mobility service tools $\left(F(2,184)=46,76, \quad p<.001, \quad \eta_{p}^{2}=.34\right)$. 

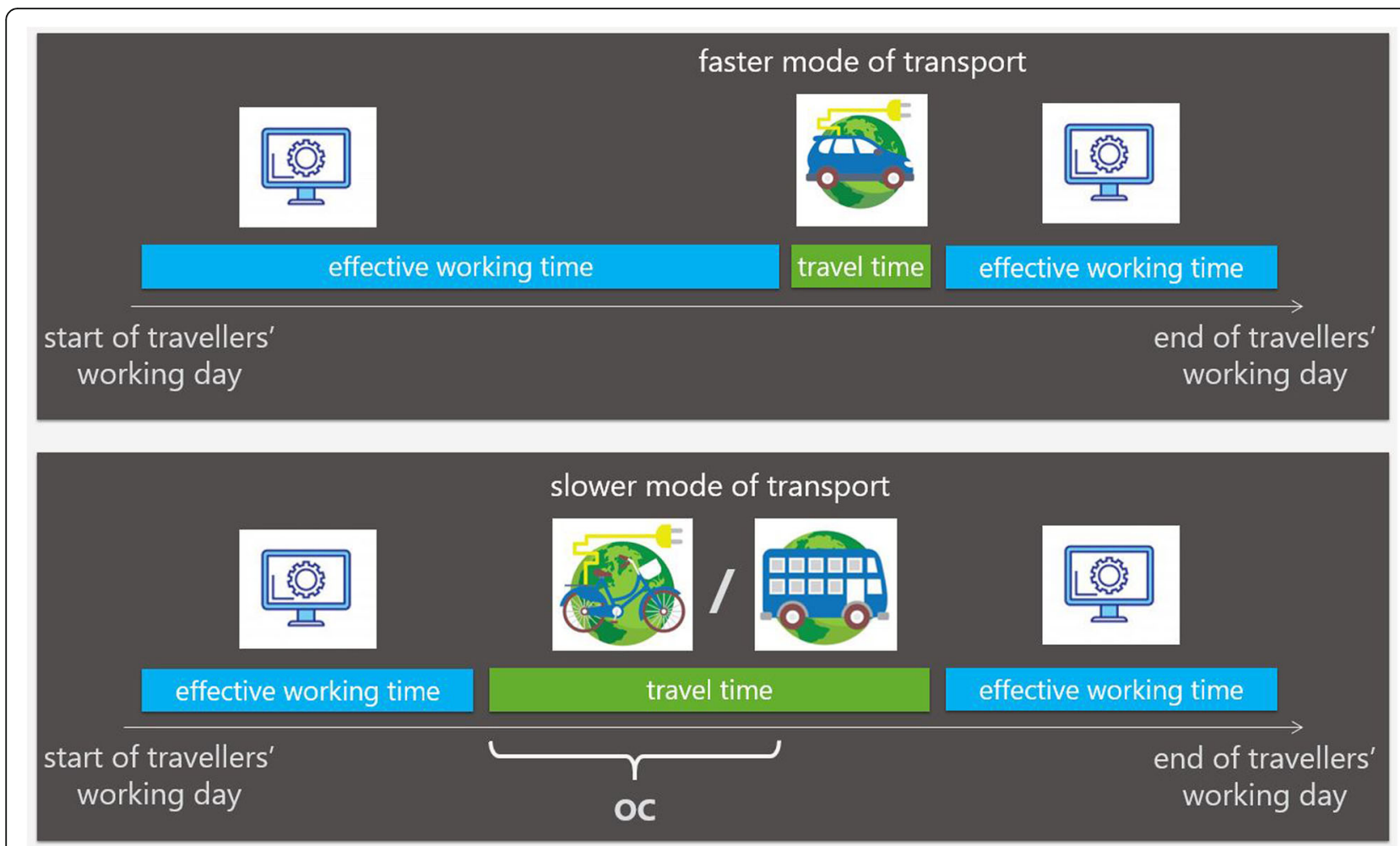

Fig. 3 The significance of opportunity costs

Bonferroni-corrected post-hoc comparisons revealed that BEVs were significantly preferred compared to public transport $(p=.010)$. There were no significant differences between attitudes towards pedelecs and public transport $(p=.093)$, as well as BEVs and pedelecs $(p=$ .461). Regarding attitudes towards the underlying mobility service tools we found strong significant differences between each tool (all $p$-values $<.001$ ). Together, these results showed that in the CMaaS system there is a strong car orientation. The BEVs and the keyless access received the highest preferences; i.e. the attitudes were the most positive $(\mathrm{Q} 1)$.
4.2 Influence of usage on user's attitudes towards the three means of transport and underlying service tools Regarding our second research question, to investigate the influence of usage behaviour on participants' attitudes we used a correlative design. Correlation coefficients (Spearman-Roh) between usage in kilometres with each means of transport and reported attitudes $\left(M_{\text {mean }}\right)$ towards the three means of transport and underlying mobility service tools are displayed in Table 3 .

Answering Q2, we found that the usage of BEVs, pedelecs and public transport was related to a more positive attitude towards the three means of transport and the

Table 2 Descriptive statistics of participants' attitudes towards the three means of transport and underlying service tools

\begin{tabular}{|c|c|c|c|}
\hline & $M_{T 1}(S D)$ & $M_{T 2}(S D)$ & $M_{\text {mean }}(S D)$ \\
\hline \multicolumn{4}{|l|}{ Means of transport } \\
\hline BEV & $4.86(1.00)$ & $4.88(1.04)$ & $4.87(.92)$ \\
\hline Pedelec & $4.73(.95)$ & $4.69(1.02)$ & $4.71(.89)$ \\
\hline Public transport & $4.53(1.13)$ & $4.44(1.18)$ & $4.48(1.05)$ \\
\hline \multicolumn{4}{|l|}{ Service tools } \\
\hline Keyless access & $5.35(.67)$ & $5.26(.97)$ & $5.31(.71)$ \\
\hline Web-based booking tool & $4.83(1.00)$ & $4.78(1.04)$ & $4.81(.89)$ \\
\hline Online ticket and corporate account & $4.16(1.29)$ & $4.23(1.29)$ & $4.19(1.16)$ \\
\hline
\end{tabular}

$N=93$. Scale ranged from 1 to 6

$M=$ Mean, $S D=$ standard deviation 
Table 3 Correlation coefficients (Spearman-Roh) between usage (in $\mathrm{km}$ ) and attitudes towards the three means of transport and underlying service tools

\begin{tabular}{lllllll}
\hline & BEV $_{\text {attitude }}$ & Pedelec $_{\text {attitude }}$ & Public transport $_{\text {attitude }}$ & Keyless $_{\text {access }}$ attitude & Booking tool $_{\text {attitude }}$ & Online ticket $_{\text {attitude }}{ }^{\boldsymbol{a}}$ \\
\hline BEV $_{\mathrm{km}}$ & $\mathbf{. 1 4}$ & -.12 & -.13 & $\mathbf{. 2 1 ^ { * }}$ & $\mathbf{. 2 2 ^ { * }}$ & -.11 \\
Pedelec $_{\mathrm{km}}$ & -.07 & $\mathbf{. 4 0 ^ { * * }}$ & -.09 & -.12 & $\mathbf{. 1 1}$ & .09 \\
Public transport & -.05 & -.01 &. $\mathbf{3 1 ^ { * * }}$ & -.03 & $\mathbf{. 2 4 ^ { * }}$ & $\mathbf{. 1 2}$ \\
\hline
\end{tabular}

$N=93 .{ }^{a}$ Online ticket and corporate account. ${ }^{* *} p=<.01,{ }^{*} p=<.05$. We used the mean attitude between T1 and T2. Attitude scale ranged from 1 to 6 . Bold marked correlation coefficients should have higher values than unmarked correlations due to content considerations

booking tool. An increased driving experience with BEVs was related to a more positive attitude towards the keyless access. Further, attitude towards the online ticket and corporate account benefited from usage of public transport. Thus, driving experience and system usage could help to positively influence users' attitudes towards and perceptions of new mobility concepts.

\subsection{Economic evaluation of costs of the three means of transport}

Addressing Q3, a basis for comparison was created with reference to the evaluated mobility data. Only two means of mobility at a time were compared with each other to ensure comparability in the variation of their ratios in the satisfaction of mobility demand. In our study setup, public transport caused the same opportunity costs arising from slower transit as taking pedelecs. But it raised higher mobility costs per distance, since more expensive single tickets had to be invoiced for flexibility and accountability reasons. Therefore, only companyowned BEVs and pedelecs were considered for this comparison.

The total business travel volume, which could be covered with the considered CMaaS solution, was derived from a previous corporate mobility study at Technische Universität Chemnitz [20]. This study included a survey in which employees were asked how often and what distances they have to travel normally. The results were interpolated to all university employees and resulted in a total distance of 418,654.67 $\mathrm{km}$ to be covered per year. Within a multimodal mobility concept it is NOT reasonable to assume the exclusive use of certain means of mobility. Rather, in such concepts, there will always be a mixed use of transport modes that has to be assessed economically. For this reason, we did not consider the costs of a CMaaS system in which only BEVs, only pedelecs or only public transport are used for our analysis, but rather compared different modal split variants. Our benchmark was formed by a $78 \%$ recourse to electric vehicles. This share of use by university employees represented the actual share observed within the field study, supported by the collected data of participants. The remaining $22 \%$ of mobility demand was assumed to be met by pedelecs. This 78:22 ratio represents
Option 1. Table 4 shows associated costs and their expected change if a higher mobility share (assumed at $50 \%$ ) is covered with pedelecs (Option 2). Based on our rough analyses of employees' travel behaviour and considering factors like distances and weather conditions, such a 50:50 ratio appears as a feasible (sustainability) goal, whereas an even higher share of pedelec usage seems unlikely to be achievable. For answering Q3, we compared these two options with each other. It becomes clear that increasing the proportion of the more environmentally friendly power-assisted bicycles leads to a significant reduction in mobility costs in the narrow sense, but overall to an increase in the total costs for business journeys. This is due to the lower speed of travel and higher opportunity costs.

Taking the available data into account, €183,556.27 per year was incurred for the operation of a multimodal mobility fleet in Option 1 which represents the benchmark. Therefore, no Opportunity Costs were accounted in Option 1. Option 2 on the other hand had an increased use of the more environment friendly means of transport, the pedelec. With respect to the slower transit, opportunity costs were included here.

\subsection{Economic comparison between a smart corporate multimodal mobility system and a conventional system with business journey accounting}

Regarding Q4, it has already been mentioned that the provision of an in-company mobility concept is an innovative alternative to established procedures in which business journey expenses are billed and reimbursed later. For the economic comparison of the two approaches for corporate mobility the administrative costs have been quantified. By using the conventional system with a business journey accounting system an average additional expense of $€ 3.47$ would be caused for each journey by the administrative effort. This was found in a previous survey and calculation [4]. Furthermore, it was assumed that a vehicle with conventional drive and no electric vehicle was used when driving a private car. In this realistic scenario, the CMaaS system was offering a further environmental benefit. It should be noted that business journeys are usually bidirectional (from the workplace to the external appointment and back), so the administrative 
Table 4 Costs of mobility caused by company-owned fleet

\begin{tabular}{|c|c|c|c|c|}
\hline & \multicolumn{2}{|l|}{ Option 1} & \multicolumn{2}{|l|}{ Option 2} \\
\hline & BEV & Pedelec & BEV & Pedelec \\
\hline Distance in km & $327,330.64$ & $92,324.03$ & $209,827.34$ & $209,827.34$ \\
\hline Costs in $€$ & $160,756.60$ & $21,279.66$ & $114,764.34$ & $42,941.86$ \\
\hline Costs per Distance in ct/km & 49 & 23 & 55 & 20 \\
\hline$O C$ in $€$ & & & $43,137.83$ & \\
\hline Administrative Costs & 1520.01 & & & \\
\hline Costs for Mobility without $O C$ in $€$ & $183,556.27$ & & $159,226.21$ & \\
\hline Total travel-related Costs for business journeys in $€$ & $183,556.27$ & & $202,364.04$ & \\
\hline Lowering of Costs in $€$ (positive $=$ saving) & & & $-18,807.77$ & \\
\hline
\end{tabular}

Option $1=$ Benchmark with 78\% BEV mobility share, Option $2=50 \%$ mobility share each

$O C=$ Opportunity Costs

effort was divided over a total of $12 \mathrm{~km}$. This represents an average round journey.

Table 5 illustrates the costs incurred by inner-city business journeys with the established procedure of business travel accounting. The results show the enormous influence of opportunity costs, which are calculated here based on the slower movement of pedelecs and public transport compared to car/BEV and not in relation to a modal split benchmark like in chapter 4.3. These economic characteristics should always be put into perspective when considering urban mobility.

The table shows that costs can be saved by providing in-company mobility solutions. Due to the considerable expense of business travel accounting, the costs for each journey are so high that the operation of an in-company mobility system is worthwhile. The time consumption that leads to additional administrative opportunity costs is illustrated in Fig. 4.

The results from Table 5 show that the savings from the elimination of cost for business journey verification and settlement are so significant that the higher costs for the in-company solution are offset. The highest savings of total travel-related costs can be expected from the provision of electric vehicles as part of an incompany solution.

\section{Discussion}

\subsection{Summary of results}

Within the present research we investigated participants' attitudes towards BEVs, pedelecs, and public transport, as well as the underlying service tools for a CMaaS systems. The attitudes towards BEVs and the keyless access process were the most positive evaluations representing a strong car orientation. Usage was related to a significantly more positive attitude towards pedelecs, public transport, the keyless access system, as well as the booking tool.

From a monetary point of view, the provision of a multimodal mobility system based on BEVs was the most cost-effective of the alternatives evaluated, which is largely due to the effects of a simplified process of business journey accounting and therefore reduced administrative costs as well as the absence of opportunity costs of slower modes of transport.

Although the mobility costs in the narrow sense of the in-company solution are higher than those of the conventional system (as reported in Table 5), no generalisable statement can be made about the economic (dis)advantage in relation to this part of total travelrelated costs. This depends on many factors like vehicle utilisation and the ownership of vehicles and the corresponding infrastructure. The dependence of the overall

Table $\mathbf{5}$ Costs and savings of an in-company mobility solution compared to costs without an in-company solution

\begin{tabular}{|c|c|c|c|}
\hline & Car / BEV & Pedelec & Public Transport \\
\hline Mobility Costs without OC in ct/km with in-company solution & 45 & 18 & 40 \\
\hline OC in ct/km caused by slower transit in comparison to car & & 37 & 37 \\
\hline Total travel-related Costs including $\mathrm{OC}$ in ct/km with in-company solution & 45 & 55 & 77 \\
\hline Mobility Costs without OC in ct/km without in-company solution & 30 & 5 & 37 \\
\hline Administrative Costs in ct/km & 29 & 29 & 29 \\
\hline $\mathrm{OC}$ in ct/km caused by slower transit in comparison to car & & 37 & 37 \\
\hline Total travel-related Costs including OC and administrative cost in ct/km without in-company solution & 59 & 71 & 103 \\
\hline Relative savings through use of in-company solution & $23.73 \%$ & $22.54 \%$ & $25.24 \%$ \\
\hline
\end{tabular}

OC = Opportunity Costs 

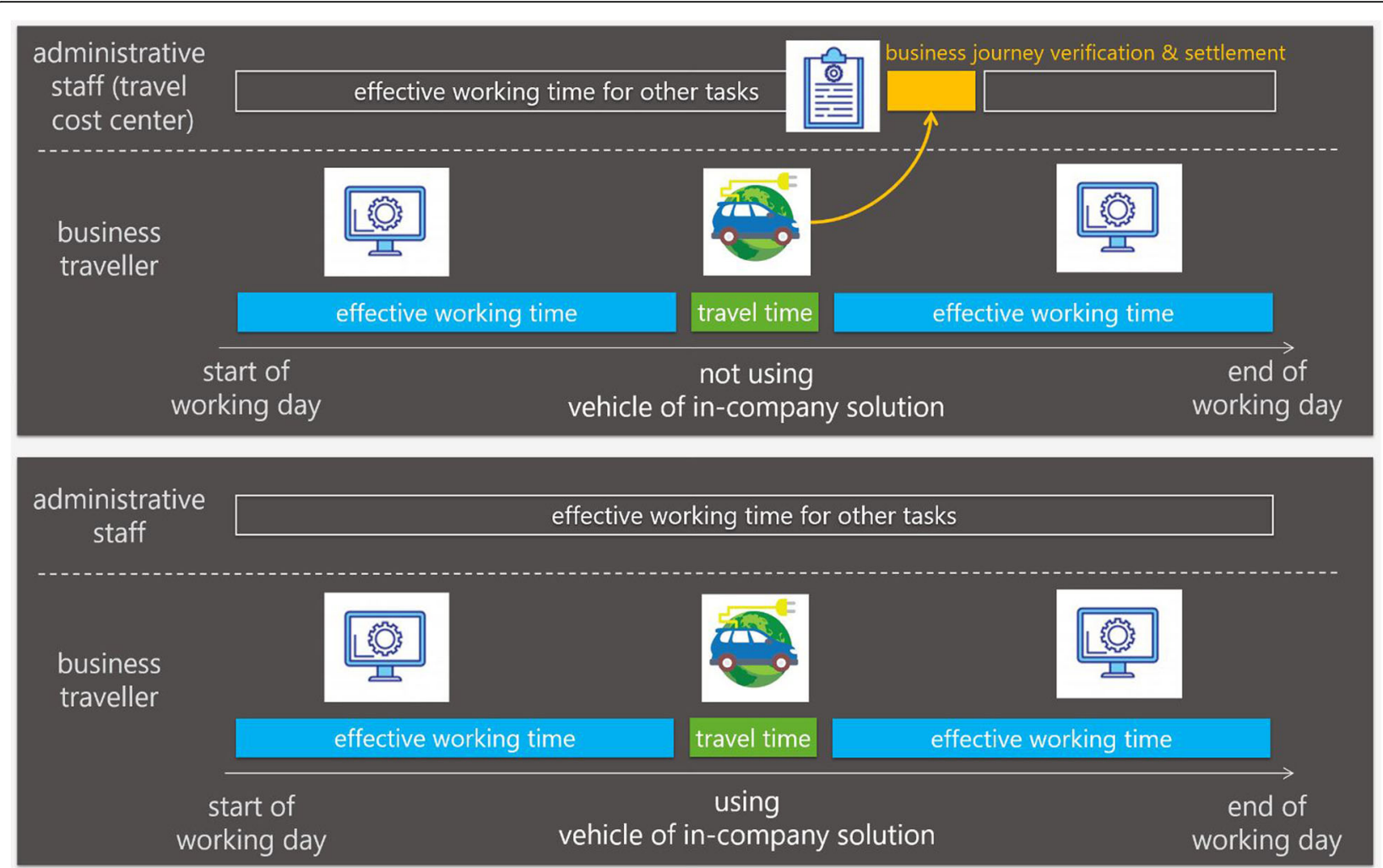

Fig. 4 The significance of administrative costs

economic advantage of the in-company multimodal mobility system is also subject to several factors.

\subsection{Implications and influencing factors}

As a result of the implementation of the CMaaS system, the proportion of business journeys by pedelec and public transport has increased significantly. According to Martin \& Shaheen [25] we were able to observe a mobility shift. Thus, offering different mobility options in a smart way is useful and necessary to increase the use of bicycles and the public transport, as well as walking.

The different attitudes towards the three means of transport and the underlying mobility service tools may indicate further improvements in dealing with multimodal mobility systems. Previous research showed that the ease of use (i.e. effort expectancy) of a corporate car sharing system was an important factor for the acceptance of this service [14]. Due to the ease of use of the BEVs and the keyless access, we assumed this was the main reason why their attitude was assessed as the most positive. The integration of the online ticket and corporate account requires an additional booking step and was therefore not optimal. Thus, we were able to strengthen previous research and could summarize that access to mobility should be designed to be as easy as possible. For CMaaS systems, this could be realised, for example, through a flexible and smart key access for cars. In our study, this could be realized by the keyless access via employee ID card. Based on our results, we would recommend a smarter integration of the pedelecs and the public transport than we could implement in the our study. Bicycles could be integrated with a digital PIN allocation system, and for the access to public transport, digital tickets or subscribers (e.g. job tickets) for employees are a recommended option.

As we found positive correlations between user attitudes and usage behaviour and as attitudes are a key predictor of behaviour [10], care should be taken to ensure that users have the opportunity to have positive experiences with the desired means of transport. For instance, test drives with a detailed briefing in the car's handling could make this possible.

Our results emphasize the importance of practical experience and usage for the evaluation of BEVs, pedelecs and public transport, as well as the underlying mobility service tools. This is in line with existing research [5]. However, in this study the attitude towards BEVs benefited only slightly from driving experience. This correlation may have been reduced due to the limited availability of the BEVs. These were the most frequently used means of transport and thus most often reserved by other users. 
According to Hesselgren, Sjöman \& Pernestål [16], work-related mobility was able to play an important role in influencing mobility behaviour. It is conceivable that positive experiences with new means of transport and attitudes gained could also influence private mobility behaviour and the choice of transport.

The examinations show that the preferable choice from an economic point of view falls on the (electric) passenger car, which is presumably the most resourceintensive mobility option. This result can be justified because of the faster travel with this means of transport (in Chemnitz) and depends on several factors.

Critical values of relevant influencing factors can be derived which lead to relative advantages of the more sustainable modes of transport (pedelecs and public transport):

- The distance to the parking space from the actual point of departure and destination is a large influencing factor on possible opportunity costs of BEV mobility (particularly in bad weather). For an ideal walking speed of $5.50 \mathrm{~km} / \mathrm{h}$, the critical parking distance of the BEV is $130 \mathrm{~m}$ when competing with the pedelec alternative and $400 \mathrm{~m}$ for the public transport alternative. At longer distances the BEV loses its economic advantage.

- The critical parking fees for cars at the destination are $€ 0.54$ when competing with the pedelec alternative and $€ 1.67$ for the public transport alternative. When parking fees are higher, the BEV loses its economic advantage.

- Positive health effects (measurable by lower absenteeism and higher productivity) can compensate for the opportunity costs of slower movement with (electric) bicycles. Employees receive additional exercises (exercise in the fresh air and cycling) on their way to the destination, which reduces their downtime. In 2014, public sector workers lost an average of 19.25 working days due to illness [7]. By eliminating one sick day per year for every 22nd mobility user, pedelec mobility would have an economic advantage. One in four users would have to record a decrease of one sick day for public transport to be advantageous.

It is obvious that the critical values shown above are not utopian values. It is therefore possible to promote more environmentally friendly and in-company mobility solutions by feasible adjustments of general conditions, e.g. political interventions with regard to public infrastructure and pricing for parking or incentive systems for healthy mobility. This falls into line with previous research suggesting that $\mathrm{CMaaS}$ offerings can be valuable at the same time from a financial, social and environmental perspective under the right circumstances [21].

\subsection{Strengths, limitations and future research}

We provided mobility data from a 22 month long naturalistic study for an urban business travel use case with high external validity. Our results may help fleet owners to further improve existing mobility concepts for corporate travel. However, several limitations should be taken into account when interpreting our results: first, our sample consisted of only 93 participants and was not representative of the German population. All participants were interested in new technologies, being welleducated university staff. Our participants were mostly men and could be characterised as "early adopters" according to Rogers [30].

Further, we only investigated urban business travel, where every journey (BEV, Pedelec and public transport) was free of charge for the user; this should be carefully considered when extrapolating from our results to make broader claims, especially for the economic evaluation of mobility.

Because it was restricted to business use only, and because only three means of transport were offered, the system was rarely used. Participants had a relatively low business mobility (i.e. on average two journeys of six kilometres per week), which was not comparable with their normal weekly mobility (i.e. including private journeys), and therefore this usage was not representative of typical daily travel in Germany [27].

In the present study we used a combination of questionnaires, driving data via the booking tool and several assumptions for the economic evaluation. The use of further methods (e.g. interviews and mobility diaries) and additional points of data collection (e.g. after 22 months of system access) would allow a more extensive database and more meaningful statements. In particular, adding qualitative research methods could provide further insights into motives, feelings and the communicated responses regarding people's decisions and actions, and open up relevant topic areas not initially considered.

The positive effects of cycling [31] or public transport [38] and the negative effects of car-based individual transport in cities [37] were not examined here.

In addition, the usage preferences and already existing resources play a decisive role in the usage prospects of multimodal mobility. In order to promote a multimodal mobility several external factors, such as the average speed (determined by the location of the mobility vehicle), the salary of travellers or fixed costs for mobility vehicles should be investigated more deeply in future research. Also the actual loss of productive working time during the use of public transport strongly depends on the individual and his environment (e.g. ideas are often 
created outside the actual workplace) and should be further investigated.

Future research should also examine adaptations of (C) MaaS solutions within rural areas, taking into account their distinct features. Such investigations will be carried out in the Smart Rail Connectivity Campus, a recently formed innovation cluster and living lab for sustainable mobility in the Ore Mountains, to whose initiators of Technische Universität Chemnitz belongs (for details, see www.smart-rail.cc).

Further interesting research questions concern the integration of CEP (courier, express and parcel) services, other modes of transport (e.g. different micro-mobility vehicles, ridesharing providers, airplanes) and automated vehicles. Investigations of possible differences between vehicle fleets used by municipal bodies and private companies, of potential benefits of shared fleet operations between several institutions and of the application in different usage scenarios, like also allowing private journeys by employees within a CMaaS system, would also be helpful. Beyond that, further research should be done regarding which modal split within (C)MaaS systems is actually preferable in the sense of environmental and social sustainability. (Social) life cycle assessment methods and integrated approaches of life cycle sustainability assessment can be used for this purpose.

Furthermore, the impact of intrinsic and extrinsic incentives to motivate an environmentally friendly and healthy mobility should be emphasised in future research.

\section{Conclusion}

The present study shows that user attitudes towards different means of transport and the underlying service tools are stable over a period of 6 months. However, results show that usage behaviour and experience with the respective means of transport and service tools can change attitudes positively. This illustrates the importance of practical usage and experiences in dealing with new technologies and alternative means of transport to promote user acceptance and positive attitudes.

Nevertheless, ease of use and a user-friendly access to the means of transport plays also an important role when choosing a mobility option. In the present study, BEVs were preferred to public transport, and there were also strong differences in user attitudes and handling between the three service tools: the tool with the easiest handling (i.e. key-less access) was rated most positively. Similar to the high preferences for the BEVs, the economic analysis showed that total travel-related costs for business journeys can be reduced by in-company mobility solutions. However, it was not possible to include all the parameters necessary for a comprehensive economic, ecological and social evaluation. For instance, it was not possible to consider the effects of vanpoolers' commuter stress [8] and physically active mobility (i.e. cycling) on the health of the employees as well as the environmental impacts of the several means of transport. For final recommendations on the selection of the means of transport in a CMaaS system in particular, and for appropriate incentives to actively promote more sustainable mobility concepts like MaaS in general, we strongly recommend conducting further studies on all sustainability dimensions.

\section{Abbreviations}

B2B: Business-to-Business; BEV: Battery electric vehicle; CMaaS: Corporate Mobility as a Service; e.g.: Exempli gratia; for example; ICT: Information and Communication Technology; ID: Identity Document; i.e.: Id est.; that is to say; M: Mean; MaaS: Mobility as a Service; Max: Maximum; Min: Minimum; OC: Opportunity costs; PIN: Personal Identification Number; Q: Research question; QR: Quick Response (matrix barcode); SD: Standard deviation; T1: Point of data collection after 4 months of system usage with online questionnaire; T2: Point of data collection after 6 months of system usage with online questionnaire

\section{Acknowledgements}

A previous version of this article [13] was presented at the International Conference on Mobility as a Service (ICoMaaS) 2019 and has been selected from the ICoMaaS 2019 papers for the Topical Collection Developing Mobility as a Service - User, operator and governance perspectives" in the European Transport Research Review journal.

The authors wish to thank all study participants.

\section{Authors' contributions}

All authors read and approved the final manuscript for submission. The authors confirm that the content of the manuscript has not been published, or submitted for publication in another journal.

\section{Funding}

The study was funded by the European Union (Europäischer Sozialfond; ESF) and the Free State of Saxony. Any views expressed herein are those of the authors and do not necessarily reflect those of the funding bodies or partners involved in the project. Open Access funding enabled and organized by Projekt DEAL.

\section{Availability of data and materials}

The datasets used and analysed during the current study are available from the corresponding author on reasonable request.

\section{Competing interests}

The authors declare that they have no competing interests.

\section{Author details}

${ }^{1}$ Cognitive \& Engineering Psychology, Technische Universität Chemnitz, 09107 Chemnitz, Germany. ${ }^{2}$ Professorship of Management Accounting \& Control, Technische Universität Chemnitz, 09107 Chemnitz, Germany.

Received: 4 June 2020 Accepted: 17 November 2020

Published online: 01 December 2020

\section{References}

1. Bamberg, S., Ajzen, I., \& Schmidt, P. (2003). Choice of travel mode in the theory of planned behavior: The roles of past behavior, habit, and reasoned action. Basic and Applied Social Psychology, 25(3), 175-187.

2. Berglund, E., Lytsy, P., \& Westerling, R. (2016). Active traveling and its associations with self-rated health, BMI and physical activity: A comparative study in the adult Swedish population. International Journal of Environmental Research and Public Health, 13(5), 11

3. Born, B., Günther, M., Jähn, B., Müller, S., Scherer, S., Temmler, A., Teuscher, J., Götze, U., Heinkel, U., Krems, J. F., Schufft, W., \& Wanielik, G. (2016). Connected Electromobility - between CO2 optimized energy management, 
user-centered design and cost effectiveness. 5. Conference on Future Automotive Technology, Munich, 03.-04.05.2016. https://mediatum.ub.tum.de/ doc/1319481/1319481.pdf

4. Born, B., Günther, M., Jähn, B., Müller-Blumenhagen, S., Temmler, A., \& Jacobsen, B. (2019). ECoMobility - Connected E-Mobility. Vernetzte Elektromobilität am Beispiel der Technischen Universität Chemnitz. Chemnitz: Universitätsverlag Chemnitz.

5. Bühler, F., Cocron, P., Neumann, I., Franke, T., \& Krems, J. F. (2014). Is EV experience related to EV acceptance? Results from a German field study. Transportation Research Part F: Traffic Psychology and Behaviour, 25(A), 34-49.

6. Cocron, P., \& Krems, J. F. (2013). Driver perceptions of the safety implications of quiet electric vehicles. Accident Analysis \& Prevention, 58, 122-131.

7. DGB. (2015). Öffentlicher Dienst: Starke Belastung und hoher Krankenstand (Deutscher Gewerkschaftsbund). http://www.dgb.de/themen/++co++40b2 7c5e-9e66-11e5-9836-52540023ef1a Retrieved on 14 June 2018.

8. Ditmore, C. J., \& Deming, D. M. (2018). Vanpooling and its effect on commuter stress. Research in Transportation Business \& Management, 27, 98-106.

9. Firnkorn, J., \& Müller, M. (2011). What will be the environmental effects of new free-floating car-sharing systems? The case of car2go in Ulm. Ecological Economics, 70, 1519-1528. https://doi.org/10.1016/jecolecon.2011.03.014.

10. Fishbein, M., \& Ajzen, I. (1977). Belief, attitude, intention, and behavior: An introduction to theory and research. Reading: Addison-Wesley.

11. Galotti, R., \& Barthelemy, M. (2014). Anatomy and efficiency of urban multimodal mobility. Scientific reports, 4 (1), 1-9.

12. Götze, U. (2004). Kostenrechnung und Kostenmanagement. Berlin Heidelberg: Springer.

13. Günther, M., Jacobsen, B., Rehme, M., Götze, U., \& Krems, J. F. (2019). Investigating user attitudes and economic evaluation of different means of transport and underlying mobility service tools in a corporate multimodal mobility system. In Proceedings of the 2nd International Conference on Mobility as a Service. Tampere: ICoMaaS, 03.12.2019-04.12.2019.

14. Günther, M., Müller-Blumhagen, S., \& Krems, J. F. (2017). The importance of acceptance for the usage of multimodal sharing Systems in Corporate Transportation. In Paper presented at ETC, European Transport Conference, Barcelona, Spain.

15. Hamer, M., \& Chida, Y. (2008). Active commuting and cardiovascular risk: A meta-analytic review. Preventive Medicine, 46(1), 9-13.

16. Hesselgren, M., Sjöman, M., \& Pernestål, A. (2019). Understanding user practices in mobility service systems: Results from studying large scale corporate Maas in practice. Travel Behaviour and Society. https://doi.org/10 1016/j.tbs.2018.12.005.

17. IVAS Ingenieurbüro für Verkehrsanlagen und -systeme (2018). Aufbau von nachhaltigen Mobilitätsketten auf der Basis von Elektrofahrzeugen unter Berücksichtigung der differenzierten Siedlungsstruktur, Verknüpfung mit dem öffentlichen Verkehr an geeigneten Knotenpunkten, Versorgung mit erneuerbarer Energie - Abschlussbericht, Dresden.

18. IVM Institut für Vernetzte Mobilität gGmbH (2016). Abschlussbericht "Perspektiven der Vernetzten eMobilität (VEReMO)" im Rahmen des Schaufensters "ELEKTROMOBILITÄT VERBINDET", Oberlungwitz.

19. Knopp, S., Biesinger, B., \& Prandtstetter, M. (2018). A resource allocation based approach for corporate mobility as a service. Technical report. Wien: AIT Austrian Institute of Technology https://arxiv.org/pdf/1810.05659v1.pdf retrieved on 21 August 2020.

20. Langer, D., Bauer, S., Dettmann, A., \& Kühnert, D. (2015). Nachwuchsforschergruppe fahrE: Konzepte für Multimodale Mikromobilität unter Nutzung lokaler regenerativer Energien, Final project report Chemnitz University of Technology, Chemnitz, Germany.

21. Lindblad, S., \& Nygårds, S. (2018). Corporate mobility as a valuable service? An exploratory study from a business model perspective. Stockholm: KTH Royal Institute of Technology https://kth.diva-portal.org/smash/get/diva2:1261712/ FULLTEXT01.pdf Retrieved on 21 August 2020.

22. Liu, Y., \& Yang, Y. (2018). Empirical examination of users' adoption of the sharing economy in China using an expanded technology acceptance model. Sustainability, 10(4), 1262.

23. MaaS Alliance (2018). Passenger Rights in Multimodal Transport - MaaS Alliance Vision Paper. https://maas-alliance.eu/wp-content/uploads/sites/7/2 018/09/Nision-Paper-on-Multimodal-Passenger-rights-240918-FINAL.pdf Retrieved on 28 Oct 2019.

24. Martin, A., Goryakin, Y., \& Suhrcke, M. (2014). Does active commuting improve psychological wellbeing? Longitudinal evidence from eighteen waves of the British Household Panel Survey. Preventive Medicine, 69, 296303.

25. Martin, E., \& Shaheen, S. (2011). The impact of carsharing on public transit and non-motorized travel: An exploration of north American carsharing survey data. Energies, 4(11), 2094-2114.

26. Metz, D. (2015). Peak Car in the big City: Reducing London's transport greenhouse gas emissions. In Case Studies on Transport Policy, 3(4), 367-371.

27. Nobis, C. \& Kuhnimhof, T. (2018). Mobilität in Deutschland-MiD: Ergebnisbericht. https://elib.dlr.de/125879/1/MiD2017_Ergebnisbericht.pdf.

28. Rehme, M., Lindner, R., \& Götze, U. (2015). Perspektiven für Geschäftsmodelle der Fahrstrombereitstellung. In Entscheidungen beim Übergang in die Elektromobilität, (pp. 409-428). Wiesbaden: Springer Fachmedien.

29. Richter, S., \& Rehme, M. (2018). Auto FipS: Automatisiertes Fahren in peripheren Siedlungsstrukturen - Potentiale zur Bewältigung demographieinduzierter Immobilität, Studie in Auftrag gegeben und finanziert vom Bundesministerium für Verkehr und digitale Infrastruktur, Förderkennzeichen: 16AVF2002A, Oberlungwitz.

30. Rogers, E. M. (2003). Diffusion of Innovations, (5th ed., ). New York: Free Press.

31. Rohkohl, S. (2017). Radfahren fördert die Gesundheit. (DAK). https://www. dak.de/dak/gesundheit/radfahren-1783876.html. Retrieved on 12 June 2018.

32. Schallmo, D. (2013). Geschäftsmodell-Innovation. Wiesbaden: Springer Fachmedien.

33. Shaheen, S. A., Cohen, A. P., \& Chung, M. S. (2009). North American carsharing: 10-year retrospective. Transportation Research Record: journal of the Transportation research Board, 2110, 35-44.

34. Sonderegger, R., Frölicher, J., Imhof, S., von Arx, W., Sträuli, C., Stadler, J., .. Schaaffkamp, C. (2018). Selbstfahrende Fahrzeuge im öffentlichen Verkehr Neue Geschäftsmodelle für die SBB im ländlichen Raum? Luzern: Hochschule Luzern.

35. Stanley, J., Hensher, D., Loader, C. (2015). Road transport and climate change: Stepping off the greenhouse gas. Transportation Research Part A: Policy and Practice, 45(10), 1020-1030.

36. Teubner, T., \& Flath, C. M. (2015). The economics of multi-hop ride sharing Business \& Information Systems Engineering, 57(5), 311-324.

37. Vienna City Administration (2014). STEP 2025 thematic concept - urban mobility plan Vienna. Wien: Urban Development Vienna.

38. VRS, (2014). Nutzen des ÖPNV übersteigt die Kosten um das Vierfache. (Verkehrsverbund Rhein-Sieg GmbH) https://www.vrsinfo.de/presse/ presseartikel/presse/nutzen-des-oepnv-uebersteigt-die-kosten-um-dasvierfache.html Retrieved on 12 June 2018.

39. Wang, Y., Wang, S., Wang, J., Wei, J., \& Wang, C. (2020). An empirical study of consumers' intention to use ride-sharing services: Using an extended technology acceptance model. Transportation, 47(1), 397-415.

40. Wosskow, D. (2014). Unlocking the sharing economy: An independent review. London: Department for Business, Innovation and Skills.

\section{Publisher's Note}

Springer Nature remains neutral with regard to jurisdictional claims in published maps and institutional affiliations.

\section{Submit your manuscript to a SpringerOpen ${ }^{\bullet}$ journal and benefit from:}

- Convenient online submission

- Rigorous peer review

- Open access: articles freely available online

- High visibility within the field

- Retaining the copyright to your article

Submit your next manuscript at $>$ springeropen.com 